\title{
PAUTAS PARA UNA FILOSOFÍA DE LA EDUCACIÓN EN SOCIEDADES EMERGENTES
}

Samuel Guerra Bravo

Pontificia Universidad Católica del Ecuador

Este trabajo pretende aportar cierta categorización, proveniente de la realidad y de la filosofía latinoamericana y ecuatoriana, para el análisis del fenómeno educativo en sociedades emergentes como las nuestras.

\section{Precisiones y delimitaciones conceptuales}

Apelando a una distinción tradicional podemos decir que el objeto material de la filosofía de la educación en sociedades emergentes es la educación vista como un todo, es decir el sistema educativo tal como se desarrolla en estos ámbitos; y que el objeto formal o aspecto bajo el cual se enfoca la educación es el de ésta tomada como capacitación y entrenamiento para una vida digna y productiva en dichas sociedades.

¿Qué es esto de sociedades emergentes? ¿Acaso no todas las sociedades son "emergentes"? Efectivamente, hay sociedades consolidadas consagradas a su autodesenvolvimiento, pero hay también sociedades en vías de desarrollo que nosotros preferimos llamarlas "emergentes" en un 
doble sentido: a) como sociedades que están en el proceso de superar condiciones históricas de sometimiento o dependencia, que "emergen" a una realización en todos los sentidos (social, político, económico, cultural), y que están saliendo a la luz de su propia comprensión y valoración; y, b) como sociedades que están en una situación delicada (en el mismo sentido en que se habla de "emergencia" en los hospitales) y que, por ello mismo, requieren de una atención y cuidado preferentes de parte de sí mismas para solucionar los problemas que les aquejan, particularmente en el campo educativo. Las sociedades latinoamericanas y ecuatorianas son "emergentes" en este doble sentido y esta característica fundamental condiciona el modo como la educación debe ser comprendida, diseñada, ejecutada y evaluada.

Hay, por tanto, una educación dada y una educación posible. La primera es la que de hecho se ha desarrollado y se desarrolla en nuestro sistema educativo en todos sus niveles (básico, medio y superior): una educación que, como se ha venido señalando reiteradamente desde hace un cuarto de siglo, presenta condicionamientos, limitaciones y deformaciones que han puesto a pensar a los especialistas en múltiples posibilidades de reforma. La segunda es aquella educación reajustada a/con nuestras necesidades esenciales de desarrollo humano, científico, tecnológico, socio-económico-político y ético. Esta "educación posible" requiere de una evaluación del sentido de la "educación dada", es decir requiere de una filosofía de la educación que la mire y evalúe como un todo desde puntos de vista estrictamente racionales. El como un todo (distintivo de la filosofía desde su nacimiento mismo) nos pondrá en contacto con el sentido global del sistema educativo e impedirá que nos extraviemos en las diversas propuestas educativas, así como en los múltiples modelos curriculares, pedagógicos y metodológicos que circulan por sociedades como la nuestra. 
Pretendemos una filosofía de la educación concreta y situada que reflexione sobre los sistemas y modelos educativos realmente existentes en nuestro contexto latinoamericano y ecuatoriano, mirados en conjunto y no en sus despliegues particulares. Para ello se requiere que la educación latinoamericana y ecuatoriana presente ciertas bases comunes y rasgos semejantes que permitan precisamente mirarla como un todo. Tales rasgos no provienen, como podría creerse, de la condición universal de educabilidad del ser humano, sino de sus realizaciones históricas, de la forma cómo ese ser humano se vuelve concreto en realidades históricas específicas, como la latinoamericana y ecuatoriana.

Como la historia lo certifica, este ámbito llamado América Latina presenta rasgos históricos comunes que determinan estructuralmente la educación en todo el subcontinente, más allá de que existan notas específicas diferenciantes en cada país. ¿Cuáles son esas determinaciones estructurales que condicionan la educación latinoamericana y ecuatoriana? ¿Cómo ellas están influyendo y determinando la orientación final y el sentido de esa educación? ¿Qué se puede hacer en el ámbito educativo para superar tales determinaciones en caso de que ellas sean atentatorias contra un desarrollo humano sano, autovalorativo, libre, soberano, democrático, intercultural?

Digamos entre paréntesis que en el ámbito de lo que podríamos llamar, por todo lo que venimos diciendo, una filosofía de la educación latinoamericana, está ocurriendo algo que en los años setenta del siglo XX ocurrió en el ámbito de la filosofía latinoamericana en general. Entonces se pensaba que la posibilidad de una filosofía latinoamericana estaba ligada a la necesidad de transformar previamente las estructuras de dependencia vigentes en nuestro subcontinente. Después, la misma reflexión 
filosófica demostró que, dentro de la situación de dependencia y sin renunciar, por supuesto, a las transformaciones estructurales (que otros llamaron "liberación"), se podía hacer filosofía latinoamericana auténtica si se pensaban precisamente las condiciones de posibilidad de la superación de la dependencia, es decir de la liberación. Algo similar ocurre ahora en el campo de la filosofía de la educación, donde sus posibilidades no dependen de que todo el sistema educativo latinoamericano se haya transformado ya, sino de que, sin renunciar a esa posibilidad, evalúe y piense las condiciones de posiblidad de una educación humanizadora y dignificadora del latinoamericano y del ecuatoriano.

Hemos dicho humanizadora, ¡es que el latinoamericano y el ecuatoriano no presentan los rasgos propios de todo ser humano o no los ejerce con la plenitud que se supone deben ser ejercidos por el simple hecho de serlo? Efectivamente, los latinoamericanos y ecuatorianos presentan la esencia y las propiedades de todos los seres humanos pero, a la vez, están impedidos de realizar muchas de las perfecciones que seres humanos en condiciones normales de autoposesión, autovaloración, autonomía, soberanía, justicia e igualdad podrían desarrollar o desplegar.

¿A qué "perfecciones" aludimos? Nos estamos refiriendo, en concreto: al uso y despliegue de la razón; a la propiedad de sí; al conocimiento de sí; al autodominio; al cuidado de sí; a la libertad, autonomía y soberanía (individual y colectiva); a la interdependencia y mutua complementariedad con otros seres humanos; a la interculturalidad; a la transculturalidad; a la visión planetaria (Morin); y al sentido de trascendencia. Estas y otras perfecciones, decimos, están gravemente dificultadas en nuestro contexto por razones históricas concernientes a la situación de "colonialidad del poder y del 
saber" (A. Quijano) vigente en nuestro subcontinente desde cinco siglos atrás. Tal situación estructural determina, no sólo los aspectos socio-económico-políticos, sino fundamentalmente los aspectos culturales, espirituales y educativos.

¿En qué sentido la colonialidad ha determinado y determina los sistemas y modelos educativos implantados en América Latina y Ecuador? En el sentido de que toda la educación (la comprensión del hecho educativo, su diseño, ejecución y evaluación) se ha organizado sutilmente en función de los intereses de los colonizadores externos e internos y no en función de las "víctimas". Paulo Freire propuso por eso una "educación liberadora", del mismo modo y con la misma intencionalidad reivindicativa con que otros propusieron una "filosofía de la liberación" (Dussel y otros) o una "teología de la liberación" (Gutiérrez y otros). La situación de colonialidad, marginación y exclusión nos confiere, por tanto, un primer horizonte para comprender, evaluar y esclarecer el sentido de lo que ha sido y es y de lo que puede y debe ser la educación latinoamericana y ecuatoriana.

Por lo pronto digamos que toda mirada racional y global acerca de nuestra educación choca contra el condicionamiento mencionado que configura nuestras formas de ser, de pensar, de actuar, de vivir y de educarnos. Pero ese es solamente un primer dato. Un segundo dato y más importante es: qué se ha hecho y qué estamos haciendo o qué podemos hacer para que el sistema educativo cambie y se ajuste a las necesidades de humanización, dignificación, descolonización, objetivación y valoración de nosotros como sujetos capaces de mirarnos a nosotros mismos, de valorarnos $y$ de proyectarnos hacia un mejoramiento o perfeccionamiento en la perspectiva muy latinoamericana $y$ ecuatoriana de un desarrollo en todos los sentidos y de un avance histórico sostenido. 
Sólo bajo parámetros críticos (con respecto a la situación actual de la educación) y propositivos (con respecto a la educación que necesitamos), una filosofía de la educación encuentra viabilidad y sentido en nuestro contexto. Ésta es entonces una necesidad histórica que, dadas las características de nuestra realidad socio-histórica, exige ciertos marcos referenciales que la hagan posible: a) un marco existencial que ubique tanto a la educación como a la reflexión sobre ella en los andariveles por los que recorre nuestra existencia; b) un marco antropológico que permita una visión del sujeto latinoamericano y ecuatoriano, pues él va a ser el sujeto de nuestra educación; c) un marco político por los aspectos reivindicativos y revalorativos que la "nueva" educación implica; d) unos paradigmas orientadores para una educación descolonizadora y reivindicativa; d) una caracterización de esa educación; y e) un muestreo de los saberes y competencias necesarios para esa educación del futuro.

\section{La dimensión ontológico-existencial de la educación en contextos emergentes}

La educación es un locus (lugar) ontológicoexistencial que tiene que ver con el ser y con el estar, con el ser-en-sí y con el ser-para-sí, con el sujeto y sus formas de manifestación y ocultamiento. Una lectura de nuestra historia permite ver cómo el(los) sujeto(s) latinoamericano ha sido invisibilizado por ese acto de magia ontológica llamada conquista, colonización, sometimiento, opresión, marginación, exclusión. La "colonialidad del poder y del saber" nos invisibilizó como seres humanos y como sujetos históricos y nos dejó visibles solamente como instrumentos a disposición del colonizador, como objetos a la mano y no como fines. 
América Latina ha enfrentado desde muy temprano esa situación ontológico-existencial tanto a través de actitudes ético-reivindicativas (Guarionex y Mayobánex en el Caribe, Tupac Amaru en el Perú), como a través del discurso estructurado (Filosofía, Teología y Pedagogía de la Liberación) y ha esclarecido parámetros educativos liberadores que en lugar de ocultarnos nos hagan visibles y permitan "vernos" en nuestra multiplicidad y diversidad, diferencia e interculturalidad. Sin embargo, la filosofía misma va detectando que este nuevo diseño educativo requiere, no sólo de paradigmas liberadores, sino de algo más profundo y decisivo: de un giro o vuelco existencial que nos coloque en la mira de nosotros mismos y haga de nosotros el referente antropológico de nuestra realidad. Tal "giro" es el producto de la razón humana que se despliega como conciencia intuitiva (impulso existencial, conatus, espíritu-alma, mente, sexto sentido, bondad natural) que accede a las claves de nuestra existencia, o como conciencia racional (capacidad cognitiva, inteligencia, entendimiento) que accede a las formas de conocimiento lógico (según un logos) o epistemológico (conocimiento propio de la ciencia).

La razón intuitiva se encarga de la dimensión existencial de los seres humanos y de los factores que la limitan o promueven; la razón cognoscitiva, de todo cuanto signifique un modo "lógico" de habérnoslas en el mundo. La razón intuitiva posibilita la intuición de nosotros mismos como existentes y atiende a las "claves" o "normas" de ese hecho "natural". La razón cognoscitiva conceptualiza, comprende judicativa o categorialmente, piensa, analiza, explica, demuestra, duda, conjetura, recuerda, olvida. La capacidad intuitiva puede "iluminar" la existencia con sus intuiciones; la capacidad lógica puede "obnubilar" (y así lo ha hecho históricamente) la existencia con sus juegos conceptuales. La una contiene 
las intuiciones fundamentales que el ser humano tiene de su propia existencia; la otra contiene modos específicos (empíricos o racionales) de comprender la existencia. Si la razón cognoscitiva se ajusta a las "normas" de la existencia tendremos una existencia "racional" y "ética"; cualquier alteración o violentación de esas normas naturales conllevará una organización "irracional" e "inmoral" de la existencia. ${ }^{1}$ La razón intuitiva es incluyente (incluye todo cuanto corresponde a la existencia humana), la razón cognoscitiva puede ser excluyente, sobre todo en contextos emergentes (puede excluir/ocultar la "normas" naturales, es decir los "derechos" naturales) e impositiva (puede imponer su "lógica", su manera de "ver" el mundo).

Pues bien, la conquista y colonización del siglo XVI significó la imposición de la razón metafísica y la religión cristiana como parámetros organizadores de la existencia indígena, lo cual significó una violentación de las claves existenciales indígenas, un vaciamiento y nihilización de sus autocomprensiones y, como consecuencia, una destrucción, ocultamiento o/y desvalorización de los modos mítico-sensitivos, empíricos, pragmáticos y autorreferidos de organización de su existencia, su realidad y su mundo. Se trató de un verdadero desfondamiento existencial, un extrañamiento de sí mismos, en su propia tierra. ${ }^{2}$

La reapropiación y el recentramiento constituyen reacciones existenciales "naturales" (exigidas por su propia naturaleza) frente a la desapropiación y el descentramiento coloniales: reacciones capaces de posibilitar un "giro existencial" que nos coloque actualmente en la mira de nosotros mismos y nos reubique como sujetos (no como objetos) en el centro natural de nuestra realidad socio-histórica y de nuestras autocomprensiones. Se trata de una verdadera intuición existencial, de un hacer/visible/el/revés/invisible en el que fue colocada nuestra existencia por obra y gracia de la razón occidental y cristiana 
y sus mecanismos de expansión y sometimiento; se trata de un redescubrirnos y mirarnos más allá o al otro lado del envés/hegemónico/excluyente de la colonialidad del poder y del saber; se trata de una vuelta a nosotros mismos, un posicionamiento autorreferido, un vernos, un colocarnos como ejes de nosotros mismos. La reapropiación de nosotros mismos es, por eso, una experiencia originaria de dignificación existencial. Luego de ella viene el trabajo de la razón cognoscitiva, de las diversas "inteligencias", de la voluntad, del alma racional y demás facultades humanas que transforman ese giro existencial intuitivo en horizonte de comprensión, en categorías organizadoras de nuestro pensamiento, en lógica, en epistemología, en cultura, en ciencia, en técnica, en civilización.

Para que ese giro existencial y el trabajo posterior de la razón (organizada en diversas formas de conocimiento, entre ellas como sistema educativo) puedan ser asimilados en su dimensión originaria, humanizante y dignificante requerimos desocultar esa razón intuitiva (que ha estado y está ocultada por innumerables conceptos y epistemes) y vernos y experimentarnos. Requerimos sentirnos y valorarnos, conocernos y amarnos, como la condición sine qua non de nuestra propia realización humana, la cual se expresa en diversos niveles de existencia y de vida autorreferida (supervivencia, emergencia, desarrollo, bienestar, interdependencia, interculturalidad, trascendencia...) y, también, en diversos niveles educativos (propiciadores de conocimiento, unos; y autoconocimiento, otros).

Una vez posibilitada esta vuelta a nosotros mismos (con lo cual superamos en el plano de la subjetividad la alienación y la autodesvalorización impuestas por el sistema) podemos ver cómo se concreta este giro existencial en el campo antropológico. Estas concreciones antropológicas servirán, a su vez, de principios orientadores para 
organizar sistemas educativos apropiados para el contexto latinoamericano y ecuatoriano.

\section{La dimensión antropológica de la educación en sociedades emergentes}

Arturo A. Roig aporta con cuatro principios orientadores que nos parecen enteramente pertinentes para el diseño de una educación humanizadora, dignificadora, reivindicativa y valorizadora de "nosotros", los latinoamericanos y ecuatorianos. Por su carácter de condiciones últimas que posibilitarían la emergencia de un nuevo sentido para nuestra educación podríamos denominarlos, siguiendo al mismo autor, como los a priori de la educación en el contexto latinoamericano y ecuatoriano: 3

\section{A priori ontológico}

Tiene que ver con el ser, y Roig resemantiza el principio del "conatus" de Baruch Spinoza que dice "toda cosa, en cuanto es en sí, se esfuerza por perseverar en su ser". 4 Según este autor, no hay nada en la cosa o en el ente (puesto que toda ella expresa la potencia de Dios) que pueda impedir su existencia y así, en cuanto puede y es en sí, se esfuerza en perseverar en su ser. Spinoza añade que el "esfuerzo con que cada cosa se esfuerza en perseverar en su ser, no es nada exterior a la esencia actual de esa cosa". 5 Todo ente y entre ellos los entes humanos persisten pues en su ser, en su existencia y lo hacen intrínsecamente, por su propia esencia. Pero Spinoza añade algo muy significativo en la proposición IX: "El alma (es decir la razón), ya en cuanto tiene ideas claras y distintas, ya en cuanto tiene ideas confusas, se esfuerza en perseverar en su ser con una duración indefinida y tiene conciencia de su esfuerzo".6 Con esto, el principio ontológico válido 
para todo ente se contrae a los entes humanos. Esto Roig lo interpreta como un giro antropológico, con lo cual el $a$ priori ontológico se convierte en a priori antropológico, la perseverancia en-sí es a la vez perseverancia para-sí: principio de autoconciencia que Hegel lo expresará más tarde con dos imperativos: "tenerse a sí mismo como absolutamente valioso" y "tener como valioso el conocerse a sí mismo".7 Con esto, Roig explicita lo que estaba implícito en el conatus (o principio conativo): que nuestro "perseverar en el ser" quiere serlo humanamente, es decir en cuanto seres valiosos y dignos. Lo de "valiosos" supone la autoconciencia; lo de "dignos" supone el hecho fundamental de que la dignidad únicamente es posible sobre la base del reconocimiento de la dignidad de sí mismo y de todo otro. Esta dignidad ontológica y antropológica es la que históricamente no ha sido reconocida ni respetada en los esclavos, en las mujeres y en los colonizados (si es que eran "dignos" lo eran por la dignidad del amo, del varón o del colonizador). Ser valioso, ser digno, para el ser humano es serlo intrínsecamente y no por dádiva externa. Esto lo expresó lúcidamente Kant cuando señaló que los seres humanos son fines en sí mismos y no medios: "Obra de tal modo que uses la humanidad, tanto en tu persona como en la persona de cualquier otro, siempre como un fin al mismo tiempo y nunca solamente como un medio". ¿Cómo llegaremos a este nivel en el que podamos ser reconocidos como fines y no como medios? Mediante el "duro trabajo", dice Roig, apelando a Hegel, el "duro trabajo" de los colonizados frente al colonizador, el "duro trabajo" de la autoconciencia, de la subjetividad, del sujeto que se autocomprende como valioso y digno y que se pone a sí mismo, desde su propia esencialidad, como valioso y digno. La "dignidad humana" aparece así como principio orientador junto a nuestras "necesidades" de descolonización y realización libre. 
"Dignidad" y "necesidades" aparecen como coesenciales: la dignidad humana, que en el caso de los latinoamericanos y ecuatorianos implica el "duro trabajo de redignificación”, es la necesidad primera de nuestra existencia. La "dignidad humana" en tanto "redignificación" se convierte en un principio que asigna sentido a todo cuanto hagamos o dejemos de hacer, tanto en nuestra existencia, como en el/los sistema(s) educativo(s). Este principio permite evaluar también a la educación como un todo, así como a las tareas educativas de todos los días en todos los niveles.

\section{A priori antropológico}

Ya hemos visto que este principio se basa en el autorreconocimiento de nosotros mismos como valiosos y dignos, pero también en el heterorreconocimiento de todo "otro" como igualmente valioso y digno. Kant reconoció la universalidad de este principio cuando lo formuló como un imperativo categórico: "Actúa únicamente de manera que puedas querer que la máxima de tu acción se convierta al mismo tiempo en ley universal". Lo antropológico se define así, no sólo en relación al sí mismo que cada uno es, sino ante todo en relación a los "otros": "duro trabajo" que no puede ser escamoteado, como hasta aquí, por nuestro sistema educativo y que, al contrario, debería orientar la organización, la ejecución y la evaluación de nuestra educación.

\section{A priori ético-axiológico}

Este a priori tiene que ver con la naturaleza intrínseca del valor del ser humano. Ya hemos visto cómo Kant postulaba el valor supremo del ser humano como fin y no como medio. Marx realizó la misma tarea, sacando a luz la naturaleza del trabajo asalariado y negando firme- 
mente que el ser humano, sobre todo el proletario, fuera un valor de uso. Cabe preguntarse frente a este a priori: ¿ el sistema educativo latinoamericano y ecuatoriano hace de los educandos fines en sí mismos o nos prepara solamente para jugar el papel de medios en el sostenimiento de las estructuras capitalistas y neoliberales dadas?

\section{A priori ético-político}

Este a priori tiene que ver con el "duro trabajo de redignificación" que estamos abocados a realizar en el plano de nuestra subjetividad (conciencia, alma, razón, mente, espíritu, libertad, cultura). En último término éste es un trabajo ético-político porque se lo realiza frente a las estructuras de la "colonialidad del poder y del saber", con la intencionalidad expresa de sumarnos a las luchas y esfuerzos por reivindicar nuestro ser (conatus), que desde el siglo XVI vienen realizando los sectores oprimidos y excluidos.

\section{La dimensión política de la educación en sociedades emergentes}

Para explicar/comprender la dimensión política de la educación en sociedades emergentes podemos echar mano, resemantizándolos para nuestros fines y para nuestro contexto, de dos modelos de reivindicación ético-política: el de Antígona (Sófocles) y el de Calibán (Shakespeare).

El "duro trabajo" de Antígona, como se sabe, consistió en desafiar al poder político del Patriarca de Tebas y enterrar a su hermano en contra de las expresas disposiciones del gobernante, sabiendo que ello le llevaría a la muerte. Eso la revistió de un "valor" y una "dignidad" que, más acá y más allá del castigo y la muerte, dio senti- 
do a su actitud y a su acto de reivindicación de su hermano y de sí misma. Fue un hecho político porque enfrentó al sistema desde su sola subjetividad.

Calibán, por su parte, aprendió el lenguaje que su amo le había enseñado para someterlo y lo redireccionó e instrumentalizó para maldecirlo por la indignidad inserta en el sometimiento.

Antígona y Calibán nos muestran de qué manera el principio de "dignidad humana" puede ser alcanzado por vía de una "redignificación" que no teme al castigo o a la muerte. Cabe entonces pensar que un sistema educativo que se fundamente o promueva la dignidad humana será, podrá ser y deberá ser, un sistema reivindicativo y revalorizador de nosotros mismos, de los demás, y de los derechos de todos. Porque el hecho de que nuestra realidad socio-política se configure a base de estratos hegemónicos y estratos subalternos, no significa que la "nueva" educación liberadora contemple el sometimiento de los actuales dominadores, sino la liberación de todos (al modo como el cristianismo auténtico lo hace con respecto a la liberación del pecado). Pues bien, ese es un hecho esencialmente político pues introduce una concepción del "poder" basado, no en el sometimiento de unos por otros, sino en el servicio a todos, reconocidos como iguales en dignidad, deberes y derechos. La educación tiene así un componente ético que le es esencial y que resulta negado, ocultado o desvalorizado por el sistema educativo, tal como está organizado actualmente. Una real filosofía de la educación debe sacar a luz estas manipulaciones de lo humano. En eso consiste también el "duro trabajo" que les compete a los filósofos, a los educadores, a las instituciones que imparten educación, y a los propios educandos. 


\section{Los paradigmas de la "Eduación Emergente"}

A partir del "giro existencial" como experiencia originaria de carácter individual y social, las sociedades emergentes y los sistemas educativos de esas sociedades necesitan desarrollar los diversos modos de construirnos a nosotros mismos. La clave que no debemos olvidar está en "vernos" y en no perdernos de vista en medio de los laberintos y argucias de la razón enajenante hegemónica y sus "ciencias". Si partimos de las necesidades y demandas del contexto en el que estamos ubicados y colocamos como valor fundamental el girar sobre nosotros mismos, el conocernos, el valorarnos y el realizarnos individual y socialmente, podemos determinar los siguientes paradigmas para la educación que requerimos en contextos emergentes:

Reapropiación de nosotros mismos, para vernos como seres humanos y no como objetos o cosas a la mano dentro del sistema hegemónico de carácter capitalista y neoliberal. Superamos con ello la deshumanización y anonadamiento que condicionan actualmente nuestra existencia individual y social;

Autorreferencialidad: convertirnos en el eje o referente fundamental de todo cuanto acontece en nuestra existencia individual o colectiva;

Reconocimiento: el redescubrirnos ante nosotros mismos y ante los otros (individuos o culturas), no sólo como existentes sino también como valiosos, como intrínseca y naturalmente valiosos; Autonomía: el autocomprendernos y autorrealizarnos bajo las normas de la existencia y dignidad humanas, válidas para el plano individual y social: propiedad de sí, cuidado de sí, aceptación 
de lo que promueve la existencia, rechazo de lo que la perturba;

Soberanía: la capacidad de controlar/gobernar nuestra existencia y enrumbarla al mejoramiento permanente y a la excelencia;

Interdependencia: el comprender que la existencia es una relación, sobre todo una relación de enriquecimiento recíproco con los demás, tanto a nivel de los individuos como de las culturas; Interculturalidad: la capacidad de viabilizar una relación igualitaria y mutuamente enriquecedora entre los componentes sociales y culturales de la realidad local (mestizos, indígenas y negros o afro-ecuatorianos) y global (todas las culturas del mundo);

- $\quad$ Transculturalidad: el no convertir las culturas en espacios cerrados de existencia sino en estar dispuestos a superar los límites o bordes culturales a favor de comunidades cada vez más grandes; Visión planetaria: nosotros somos realidades históricas y sociales localizadas y específicas; pero, igual que nosotros, hay otras múltiples y diversas realidades históricas y sociales más allá de nosotros, a las cuales debemos abrirnos con visión planetaria, sin renunciar a las propias especificidades;

- $\quad$ Trascendencia: la lucha por mejorar y superar el nivel existencial en el que nos encontramos y la búsqueda de horizontes cada vez más amplios, globales, planetarios, para nuestro desarrollo y progreso, pero también más humanos para la convivencia y reciprocidad.

¿Cómo diseñar un sistema educativo que transforme la alienación en autoafirmación, el encubrimiento 
en reconocimiento, la exclusión en autorreferencialidad, la opacidad histórica en luminosidad? ¿Es esto, acaso, posible? Debemos responder categóricamente que sí es posible porque el reposicionamiento en el plano de lo humano que acaece a nivel de la subjetividad individual puede enseñarse-aprenderse mediante la educación y convertirse poco a poco en un proceso social e histórico.

La apropiación de nosotros mismos, de la que venimos hablando, cuenta ya con un camino abierto por nuestras generaciones pasadas. Tal historia es un referente necesario para las generaciones presentes. Si a ello añadimos la necesidad, demanda, impulso, decisión y coraje actuales para redescubrirnos y reencontrarnos, para creer en nosotros mismos, para reconocernos como valiosos y, luego, probarnos a nosotros mismos que somos capaces, que podemos hacerlo, que lo hacemos, que lo logramos, tenemos un cuadro de condiciones favorables para recoger y valorar lo que podrá denominarse "nuestra" historia, que la hacemos desde el presente hacia el futuro recogiendo los legados de las generaciones pasadas y las expectativas de las generaciones presentes. Porque la historia de la reapropiación y la autorrealización no comienza ahora, empezó ya desde el momento mismo en que históricamente se produjo en nuestra América la desapropiación y la deshumanización coloniales. La historia como saber de nosotros mismos, la tradición, la contextualización, la desideologización, constituyen instrumentos adecuados para hacer visible, leer, comprender, autorreferir, utilizar y evaluar lo acaecido en el pasado, lo que acaece en el presente y lo que acaecerá en el futuro (en la medida que podemos pre-verlo desde ahora). Todo esto es ejecutable y evaluable a través de sistemas educativos coherentes con las necesidades existenciales, antropológicas, políticas y educativas de sociedades emergentes. 


\section{Los caracteres de la "Nueva" educación}

El concepto de "educación" en el contexto ecuatoriano-latinoamericano requiere ser ampliado, por tanto, para que atienda, además de los contenidos científico-técnicos, a este reposicionamiento de los latinoamericanos y ecuatorianos en el plano de lo humano. Lo usual es que se considere al sistema educativo como estructurado por y para los conocimientos científico-técnicos. Pero ya sabemos que un sistema educativo "emergente" (humanizante, dignificante, valorizador) debe atender también a los aspectos existenciales y axiológicos señalados arriba. En tanto educación científico-técnica, el sistema educativo se encuadra en las actuales geopolíticas epistémicas globales; en tanto giro existencial autoafirmativo y autovalorativo, el sistema educativo deberá acoger y recoger nuestros saberes existenciales e históricos.

Este enfoque nos dará la clave para encuadrar (darle un marco) al conocimiento llamado "universal", por una parte, y para valorar nuestros saberes históricos e incorporarlos a los procesos educativos, por otra parte. De este modo, también, el sistema educativo dejará de reproducir acríticamente tanto la colonialidad del poder (con sus geopolíticas socio-económicas) como la colonialidad del saber (con sus geopolíticas epistémicas), aprovechará del saber científico-técnico proveniente de cualquier parte y lo redireccionará hacia nosotros mismos como sujetos educativos y hacia nuestro desarrollo, progreso y bienestar.

Esto significa que el sistema educativo de/para sociedades emergentes requiere también de un giro o vuelco estratégico de tal modo que se fundamente, no en el conocimiento o en epistemes universales, supuestamente asépticas y neutrales, sino en nosotros mismos, en nuestras necesidades y proyectos de autorrealización. Esto 
no implica, lo enfatizamos, descartar el conocimiento científico-técnico; significa solamente reorientarlo de tal manera que en lugar de hacerle el juego, implícita o explícitamente, a los intereses de la actual colonialidad del poder y del saber, sirva para el conocimiento, comprensión, realización y promoción de nosotros mismos.

¿Por qué seguir reproduciendo todos los días nuestra colonialidad en las aulas? ¿Qué tal si desideologizamos y desabsolutizamos los saberes epistémicos impuestos y los estudiamos, sí, pero instrumentalizándolos para nuestros fines autorreferidos? ¿Qué tal si valorizamos y potenciamos nuestros saberes existenciales e históricos y los convertimos, junto con los saberes epistémicos desideologizados, en objeto de estudio académico? ¿Qué tal si en lugar de organizar el sistema educativo como mecanismo de alienación y sometimiento, lo organizamos como sistema de autocentramiento, autovaloración, autorreferencialidad, reconocimiento, autonomía, soberanía, interdependencia, interculturalidad, transculturalidad, visión planetaria y trascendencia? ¿Qué tal si convertimos al sistema educativo en mecanismo de reencuentro con nosotros mismos y, a la vez, en mecanismo de apertura al mundo, a la ciencia, a la globalización, a la interculturalidad mundial?

El sistema educativo de/para sociedades emergentes debe instrumentalizar y potenciar los conocimientos de cualquier parte enmarcándolos en nuestros objetivos históricos, pero se encargará también de desarrollar las capacidades y habilidades que requerimos para la descolonización y la emergencia (autofundamentación, autovaloración, autorreferencialidad, autoestima, autocontrol, etc.). De ese modo, nuestro educando será capacitado y desarrollará habilidades para navegar en el complejo mundo de lo extraño, lo propio y lo "apropiado"; de lo especulativo, lo empírico y lo pragmático; de lo metafísi- 
co y lo histórico; de lo ideológico y desideologizado; de lo esencial abstracto y lo existencial concreto. Esto significa que podrá navegar en el complejo mundo de los conocimientos epistémicos, los procedimientos, las actitudes y los valores y, además, en las inciertas fronteras entre lo uno y lo múltiple, lo diverso y lo diferente, lo distinto y lo intercultural.

Para navegar en el complejo e incierto mundo en que vivimos se requieren, como hemos dicho arriba, referentes o señales que nos orienten y señalen el camino. Educar será entonces enseñar/aprender conocimientos, pero será también desarrollar la capacidad de orientación para no perdernos en los vericuetos de la episteme moderno-occidental y de la globalización actual. Identificar los problemas vinculados al campo cognoscitivo-científicouniversal, al existencial-histórico-específico, analizar dichos problemas, sintetizarlos, decidir qué hacer, actuar, evaluar, familiarizarse con los cambios, con los comienzos y recomienzos: eso será educar en el futuro.

\section{Contenidos, capacidades, destrezas y habilidades de/para una educación autorreferida}

Una vez concentrada la educación (de conocimientos epistémicos y saberes históricos) bajo las coordenadas de nuestra existencia y sus imperativos históricos, se cultivarán las capacidades, destrezas y habilidades correspondientes, que tienen que ver con la razón cognitiva, por una parte, y con la sabiduría histórica autorreferida, por otra parte.

En el campo de los conocimientos epistémicos desideologizados será imprescindible el aprendizaje significativo del lenguaje y la comunicación (gramática, literatura, retórica), del cálculo (matemáticas, ciencias exactas), de la ubicación física (geografía, ciencias naturales, biolo- 
gía, ecología), de la contextualización, desideologización y globalización (historia, sociología, economía, política, en relación con la geopolítica, geoeconomía, geocultura).

En el campo de los saberes existenciales estratégicos será imprescindible el estudio de legados históricos reivindicativos y autovalorativos de generaciones anteriores, así como el entrenamiento mental para el giro existencial intuitivo de las generaciones actuales, como para los procedimientos, actitudes y valores relacionados con la reapropiación de nosotros mismos, el autoconocimiento, la autorreferencialidad, el reconocimiento, la autovaloración, la autonomía, la soberanía, la interdependencia, la interculturalidad, la transculturalidad, la visión planetaria y la trascendencia.

En el complejo mundo en que vivimos, los individuos, las colectividades y las culturas requieren aprender todo cuanto concierne a un desenvolvimiento adecuado ante la vida, el trabajo, la subsistencia, el desarrollo, el progreso, el bienestar, el éxito. Existe ya un corpus teórico que la humanidad en general y nuestras propias culturas han construido y desarrollado, y que es necesario conocerlo y aprenderlo. Esta es una responsabilidad de la que nadie está exento y el sistema educativo emergente deberá seleccionar tanto los "saberes epistémicos" (conocimientos) como los "saberes existenciales estratégicos" (sabiduría histórica) que realmente sean fundamentales para las necesidades, demandas y retos del siglo XXI.

La educación "emergente" deberá organizarse en torno a aquellos conocimientos, capacidades, destrezas y habilidades que promuevan, valoricen, potencien y visibilicen nuestra condición de individuos y culturas locales y globales. ¿Y cuáles son esos conocimientos? Pues aquellos que nos permitan hablar y comunicarnos, posicionarnos en el mundo y en la historia, entrar en la economía y en la sociedad, participar en la política y en la cultura. 
Pero, también, la "educación emergente" deberá enseñar cómo orientarnos, no sólo en el mundo cósmico (orientación física), sino sobre todo en el mundo de los seres humanos (orientación antropológica), en el del pensamiento (orientación lógica y epistemológica), en el mundo social (orientación social), y en el juego de contextos locales y globales (orientación geopolítica). En la medida en que los educandos del futuro desarrollen las capacidades y habilidades para orientarse en el mundo local y en el global, podrán convertir las realidades locales y globales en escenarios de su autorrealización.

Orientarse en el contexto ecuatoriano-latinoamericano supone moverse ágilmente en una red de determinaciones provenientes de la colonialidad del poder económico, político y epistémico, por un lado, y de las necesidades y urgencias vinculadas a los procesos de reapropiación y autovaloración, por otro lado. En el ordenamiento actual de las cosas, las primeras (las determinaciones provenientes de la colonialidad) cumplen un papel ocultante y desvalorizador; las segundas (las determinaciones provenientes de los procesos de reapropiación y autovaloración) cumplen una función desalienadora, humanizadora y valorativa.

La clave está en autocomprendernos y asumirnos como una experiencia histórica que requiere, sí, su categorización y conceptualización, pero no al modo de una definición metafísica [del tipo "el hombre es un animal político" (Aristóteles), "el hombre es animal racional" (Escolástica), o "el hombre es una caña pensante" (Pascal), o "Yo soy mi libertad" (Sartre), o cualquier otra], pues las definiciones metafísicas apriorísticas (anteriores a toda experiencia histórica) condicionan o coartan la construcción de sujetos históricos autocentrados, sean individuales o colectivos. En el caso del contexto ecuatoriano y latinoamericano, el giro existencial funda la posi- 
bilidad de la metafísica, y no al revés. El pensar, categorizar, conceptualizar, elegir, decidir, actuar, evaluar, etc. son y serán manifestaciones de esa experiencia autocentrante que apunta, a fin de cuentas, al encuentro con nosotros mismos, a nuestra autoconstrucción (y, por consiguiente, a la vida autorreferida o buen-vivir, a la felicidad, a la verdad y al bien individual y colectivo).

Por lo dicho, el sistema educativo de/para sociedades emergentes jugará un papel central tanto en la enseñanza/aprendizaje de los conocimientos epistémicos universales, como de la sabiduría histórica autorreferida. Se trata, a fin de cuentas, de educar para un correcto desempeño en la vida, en el trabajo, en la profesión, los negocios, el desarrollo, el bienestar, la felicidad, la solidaridad; y para el desarrollo de las capacidades, competencias, destrezas, aptitudes y habilidades necesarias para orientarnos en el espeso bosque de los conocimientos y de las situaciones históricas cambiantes.

Todas las reformas educativas de fines del siglo XX bebieron de esta necesidad. Su debilidad, sin embargo, que pronto quedó de manifiesto, es que se plantearon como reformas cognitivas, procedimentales, actitudinales y como reenfoques del pensar (aprender a pensar), hacer (aprender a hacer), ser (aprender a ser), vivir (aprender a vivir juntos), pero nunca como un reposicionamiento existencial. Las reformas más visionarias hablaron de reforma de valores; eso fue un gran paso, pero insuficiente si el ámbito cognitivo, procedimental, actitudinal y valorativo no está mediado, como debería estarlo en regiones emergentes, por una conversión existencial que permita "vernos", "reapropiarnos", "valorarnos". Dicho de otro modo: una reforma educativa no es efectiva en contextos emergentes si, previamente a los cambios en los currícula, no ponemos por delante esa vuelta a nosotros mismos. Sólo entonces será posible el conocimiento y el 
autoconocimiento, la valoración y la autovaloración, la asimilación de lo extraño y lo propio.

De este modo, el objetivo de la educación emergente será el de formar sujetos capaces de manejar hábilmente tanto la "razón epistémica" como la "razón existencial", de tal manera que podamos desenvolvernos con idoneidad tanto frente al maremágnum de conocimientos científico-técnicos e influjos provenientes de todas partes, como frente a la urgencia y necesidad de reapropiarnos, reconstruirnos y proyectarnos históricamente.

\section{Condiciones subjetivas y objetivas para un sistema educativo autorreferido}

La "capacidad" de intuirnos como valiosos, opacada u ocultada por la colonialidad del poder y del saber, requiere ser educada, más bien "reeducada", de tal modo que el educando se "vea" a sí mismo como sujeto (sujetividad) y como miembro y agente de una determinada realidad histórica desde la cual se abre a la realidad global. No hay apertura a la globalidad sin una previa ubicación en la localidad; si no se parte de lo local entonces no habrá "apertura" sino subsunción, inmersión indiferenciada en la globalidad, es decir autoocultamiento y autodesvalorización. Pero este sentido y ubicación en lo local sólo puede darse cuando el educando se apropia de sí mismo sin cerrarse y emprende en los respectivos procesos de auto y héterorreconocimiento, que asigna sentido a los demás procesos de autorreferencialidad, autonomía, soberanía, interdependencia, interculturalidad, etc.

Las condiciones subjetivas de los educandos en sociedades emergentes estarán, por tanto, emparentadas con las demandas configuradoras de una existencia autorreferida: humanización, historicidad, autofundamentación, contextualización, autorreferencialidad, autovalora- 
ción, autoestima, autocontrol, demandas que responden en suma a dos objetivos históricos actualmente vigentes en Ecuador y América Latina: la descolonización y la autoafirmación (tanto en sentido individual, como en sentido colectivo y cultural), por un lado, y la contextualización y globalización, por otro lado.

Las condiciones objetivas de la educación del futuro tienen que ver con la configuración actual de nuestro contexto y del mundo en el plano social, económico, político, cultural, científico-técnico, etc. Sin entrar en análisis socio-económicos, podemos señalar los siguientes condicionamientos que funcionan actualmente en estos contextos y que ningún sistema educativo debe olvidar: unipolaridad; globalización; neoliberalismo económico; darwinismo social; democracia representativa; alienación cultural; cientificismo, racionalismo y tecnología como mecanismos de poder y control; invasión o vaciamiento cultural permanente; despotenciación de las historias locales; ocultamiento o desvalorización de los conatos reivindicatorios; desacreditación e invisibilización de lo emergente, lo local y diferente; nihilización de los núcleos ético-mítico-simbólicos. Frente a estas condiciones objetivas alienantes debemos reconocer también otras condiciones objetivas desalienantes, fruto del esfuerzo y lucha de nuestras sociedades emergentes por permanecer en la existencia (conatus) y por ser reconocidos como fines en sí y no como medios: movilización, resistencia, disenso, ciudadanía, dignificación...

Esto significa que la "educación emergente" no se guía solamente por las determinaciones objetivas alienantes, sino que las contrarresta con una educación de la subjetividad (de nuestra autoconstrucción como sujetos) que saca a luz y hace visible aquello que la unipolaridad hegemónica oculta o desvaloriza: nosotros mismos, lo local, lo transversal, lo diferente, lo intersticial, lo fronte- 
rizo, lo interdependiente, lo intercultural, lo específico, lo mental, lo mítico, lo simbólico.

Llegamos, una vez más, a una misma conclusión: que la educación de/para sociedades emergentes deberá ser epistémica y existencial. Epistémica: racional, científica, técnica [lo cual requiere sin embargo que se ponga por delante el hecho de que la episteme occidental no es ni universal ni neutral, ${ }^{9}$ y que requiere de contexlidades emergentes) y desideologización (refuncionalización, apropiación, asignación de sentido y utilización para nuestros fines)]. Existencial: que desarrolla capacidades, destrezas y habilidades en el educando para redescubrirse, reapropiarse de sí mismo, reconocerse, revalorarse; para autorreferir todo cuanto aprende; para garantizar desde sí mismo su propia autonomía, soberanía, interdependencia, interculturalidad y trascendencia. La educación del futuro será de este modo integradora y sintética, pues reunirá los saberes científico-técnicos y los saberes existenciales $e$ históricos y los condensará en una visión nueva, pero propia, una visión enriquecida, creativa, abierta, multidimensional, polifuncional.

\section{Notas}

1 ¿Cuáles son esas "normas" de la existencia "natural"? Los estoicos mencionaron al menos cuatro: la propiedad de sí, el cuidado de sí, el atraer todo lo que conviene a la existencia, el rechazar lo que perturba la existencia.

2 Un modo distinto de habérselas con el mundo, una racionalidad, una "lógica" distinta a la de los indígenas precolombinos, un nuevo sistema organizador de la existencia humana se impuso de hecho en el siglo XVI, a raíz de la conquista y colonización de nuestra América. Se trató, como todos sabemos, de la razón/metafísica/medieval/europea refugiada en España: una racionalidad espiritualista, especulativa, universalista, abstracta, 
trascendentalista, idealista, intemporal, monoteísta, supuestamente necesaria y absoluta, que desplazó a las formas de autocomprensión míticas, sensitivas, empíricas, pragmáticas, valorativas y autocentradas de las culturas andinas. Al desplazar España los núcleos ético-mítico-simbólicos que organizaban la existencia andina, colocó a nuestra culturas indígenas en situación mental y real de ostracismo, desorientación y descentramiento. De esta manera, los fundamentos de la colonialidad quedaron puestos en el siglo XVI; el resto (lo que vino después) fue la organización socio-económico-político-cultural del sistema colonial.

3 Cfr., Ética del poder y moralidad de la protesta. La moral latinoamericana de la emergencia, Quito, Universidad Andina Simón Bolívar, Sede Ecuador, y Corporación Editora Nacional, 2002, pp. 75-79.

4 Ética demostrada según el orden geométrico, Buenos Aires, Editorial Aguiar, 3a . parte, proposición VI, 1961, p. 184.

5 Op. cit., Proposición VII, p. 184

6 Cfr. Ética..., p. 185.

7 Cfr. Roig, op. cit., p. 76.

8 Cfr. Roig, op. cit., p. 77.

9 Hace tiempo ya, Jürgen Habermas demostró el carácter ideológico de la ciencia y la tecnología. Ver Ciencia y técnica como "ideología”, Editorial Tecnos, Madrid, 1997, pp. 53-112. 



\section{MUJERES INDÍGENAS LÍDERES Y ESCUELA}

Gabriela Bernal Carrera

Fundación Kawsay

\section{Introducción}

El presente artículo pretende mostrar algunas de las características de la relación entre mujeres indígenas serranas y escuela ${ }^{1}$ entre 1970 y 1990, aproximadamente. Tras la desintegración de la hacienda como mecanismo de administración de la población indígena, la escuela se convierte para la población indígena en un mecanismo para ir articulando un proyecto capaz dar forma a sus intereses políticos.

Con la reforma agraria, la población indígena se convierte en propietaria de la tierra; a partir de este hecho se puede vislumbrar el establecimiento de las bases para una diferenciación socioeconómica en la población indígena. El ingreso a la escuela se convierte en un mecanismo de acceso a la sociedad nacional a partir del aprendizaje del castellano.

El sistema educativo formal se mostrará como un espacio hostil y, en muchos casos, brutal. Sin embargo, la escuela permitirá que, al salir del espacio comunitario, se inicie la autopercepción de la diferencia. En el caso de las mujeres indígenas, el duro cambio supuso una doble discriminación: por indígena y por mujer. Pero el acceso a la escuela también les abrió la puerta a mundos como el 